\title{
Implications of a smoking ban on submarines in the US Navy
}

MJAFI 2012;68:199

Submarines in the world can be broadly divided into two groups: the conventional diesel-electric submarines, and the newer nuclear powered ones. Conventional submarines, unlike ships, are propelled by a motor drawing power from batteries which are charged by diesel generators. Diesel generators draw air for combustion by raising a snort mast with the submarine just below the surface. 'Snorting' and charging of batteries is usually done once daily for 4-8 hours. Nuclear powered submarines, on the other hand, draw power from batteries charged by electricity drawn from the nuclear plant and hence, do not require to snort which in turn allows them to stay underwater for prolonged periods ranging from weeks to months.

Smoking on board the diesel-electric submarines is permitted during snorting and that too only in the engine room where the smoke is sucked in by the engines and released with the engine exhaust. Nuclear submarines do not have such a provision and some countries have therefore catered for specially designed smoking chambers fitted with air purification systems like carbon monoxide burners, carbon dioxide scrubbers, ionized particulate precipitators, mesh filters, and activated charcoal filters.

Unites States Navy recently banned smoking on board its entire fleet of nuclear submarines after the discovery of high levels of urinary cotinine in non-smokers indicating exposure to negative effects of tobacco despite air purification systems. Urinary cotinine is a known metabolite of nicotine and has been shown to be an excellent marker for nicotine exposure from active or passive tobacco smoke. In the study conducted by US Naval Submarine Medical Research Laboratory (NSMRL), the average urinary cotinine level doubled after a deployment of at least three months and increased even more if corrected for self-reported exposure to environmental tobacco smoke while in port. ${ }^{1}$

A decision to completely ban smoking on board the nuclear submarines can have far reaching consequences. Submarine operations are inherently stressful and watch keeping inside a submarine involves high levels of concentration and takes a heavy toll on the crew leading to mental fatigue. In such an environment, smoking is often a very useful stress relieving tool available to the crew. ${ }^{2,3}$ For smoking cessation, two strategies are often advised: abrupt cessation, and gradual tapering. Abrupt smoking cessation can be stressful and lead to acute development of withdrawal symptoms whereas gradual tapering would lead to lowering of blood nicotine levels below a critical level and gradual precipitation of withdrawal symptoms leading to chances of relapse. ${ }^{4}$ Despite the approach, development of withdrawal symptoms by a crew member could be disastrous inside a submarine. Administration of nicotine replacement therapy along with behavioural therapy has been recognised as a valuable modality in assisting individuals to quit. Keeping these concerns in mind, US Navy has introduced a smoking cessation programme which includes provision of nicotine replacement therapy in the form gums and patches along with exhaustive cessation training and support programme to assist crew in kicking the habit. ${ }^{1}$

In the Indian context there are important lessons. As the Indian Navy aspires to operate nuclear submarines in the near future, there will be a need to take a call on the smoking habits of the officers and sailors who have been, or will be selected in the future to crew the nuclear boat. Traditionally, there has been a no flame policy on board the current fleet of dieselelectric submarines (except during snorting and that too only inside the engine room) and as the study under reference has shown, because of the health risk to the non-smokers, smoking will have to be disallowed inside the nuclear submarine during deployment. Therefore, the Indian Navy will have to design and put in place, a smoking cessation programme for the selected crew of the nuclear boat so as to make their transition into the strict no smoking environment easier and less stressful.

\section{REFERENCES}

1. Shah AN, Arnold MJ. Military Medicine 2011 Feb. Available from: http://findarticles.com/p/articles/mi_qa3912/is_201102/ai_ $\mathrm{n} 57035900 /$ ?tag=content; col1.

2. Jackman RP, Willette PN, White D, Krizek SM. Minimizing exposure to passive smoke in the enclosed environment of US submarines. Aviat Space Environ Med 2004;75:60-64.

3. Bushnell FK, Forbes B, Goffaux J, Dietrich M, Wells N. Smoking cessation in military personnel. Mil Med 1997;162:715-719.

4. Rennard SI, Hepp LM, Daughton DM. Cigarette smoking and disease. In: Fishman's Pulmonary Diseases and Disorders 4th ed. McGraw Hill 2008:747-761.

Contributed by Surg Lt Cdr Sourabh Bhutani*, *Graded Specialist Marine Medicine, INS Shankul, C/o Fleet Mail Office, Mumbai - 400001. 